clature is too erude and static to encompass the restless mutatings of living things, but at least the effort would be praiseworthy. Besides, it is demoralizing for any scientist to have to keep on repeating what he does not wholly believe.

It is sad to find that Dr. Butcher has joined forces with those who require a popular name for every unpopular plant: one senses political undertones in 'Red German Catchfly' (Lychnis viscaria), redressed perhaps by the fact that Rumex orientalis has escaped to become the 'Western Dock' and-it was bound to happen sooner or later-one blushes at the frankly clinical implications of Dickie's Bladder Fern. How fortunate that Cystopteris dickieana is such a very rare plant !

Finally, it must be pointed out that the Achlamydeae, Group VI (p. 37) in the mammoth identification key, do not have "both calyx and corolla prosent".

R. D. MEIKLE

\section{THE MITES AND TONGUE-WORMS OF AFRICAN VERTEBRATES}

The Arthropod Parasites of Vertebrates in Africa South of the Sahara, (Ethiopian Region)

Vol. 1 (Chelicerata). Edited by F. Zumpt. (Publications of the South African Institute for Medical Research, No. 1, Vol. 9.) Pp. vi +457. (Johannesburg: South African Institute for Medical Research, 1961.) R. 6.00 .

T 'HE "onlie begetter" of this handsome volume was undoubtedly the Check List of the late G. A. H. Bedford, published during 1927-36, a fact which is acknowledged in the first sentence of its introduction; it would perhaps have added a further touch of graciousness if it had been made clear that the very form of the present compilation is that inaugurated by Bedford-keys, figures, method of specific citation, sections, notes and even the general typography. Bedford's achievement was a great one, and to admit it to be so does not in the least diminish one's admiration for the extreme care and competence of all the authors of this, Bedford's successor.

Three decades of research in this field have increased the numerical total of Bedford's Check List many times and the present volume adds numerous new and excellent figures and completely new keys. The extreme care which has been taken by all the authors can be seen in the treatment of 'difficult' genera, for example, Haemolaelaps. A conservative systematics is evident everywhere, and if some acarologists feel that occasionally this conservative constraint may obscure some important relationships (as in some feather-mite genera), none, at least on the eastern side of the Atlantic, but will welcome the consequently rational treatment such as is accorded the Trombiculidae, in which family the fluidity of present-day generic concepts is frankly recognized and reflected.

The general introductory discussion of arthropod parasitism is succinct and reliable, and, within the obviously set limits which have been imposed, gives a useful survey of the subject for the purposes of the general student; but it leaves unanswered, of course, several problems such as why, for example, there are different patterns in the reduction of the biological cycle of the Acari. In this connexion it might be mentioned that the extremely complicated matter of the evolution of parasitism in the Trombidiformes is clearly if rapidly sketched, but one imagines that there will be several workers who will share my resistance to the suggestion that the Ereynetidae have evolved. from "Trombicula-like" ancestors.

It seems ungrateful, given here so much, to ask more, but one could have wished for a system of cross-references between the bibliographical citations and the records. This would have made for easy validation of the latter, and although the specialist can perhaps often make an intelligent guess, the non-specialist has the labour of working systematically through all the entries. Optat ephippia bos piger, optat arare caballus. $\quad$ F. A. TURK

\section{FIFTY YEARS OF STEDMAN}

\section{Stedman's Medical Dictionary}

Twentieth edition, completely revised. Pp. xlvii + $1680+31$ plates. (London: Baillière, Tindall and Cox, Ltd., 1961.) 1108 .

A NY published work which has run into its twentieth edition has proved its worth. In 1911, Thomas Lathrop Stedman compiled the first edition of his medical dietionary which, compared with the latest, was relatively so simple that he needed no collaborators.

When the present work was projected, a team of experts in the various phases of medical lexicography was brought together to act not as advisory consultants but as working partners. These twenty-three consulting editors include such names as Prof. A. I. Lansing, C. D. Leake, and N. B. Taylor, and are supported by outstanding colleagues in the fields of dentistry and pharmacology. Together they have scrutinized each entry in the nineteenth edition, re-defined many thousands of them and inserted a vast number of new ones. Each entry carries with it, if necessary, a reference to the appropriate anatomical or pharmacological nomenclature, while tables are used for many sorts of entries, for example, methods, operations, diseases, anatomical structures and pharmacological terms.

One difference between this and other modical dictionaries is that it carries many dental terms; the volume will be equally useful to dental practitioners and students as to members of the medical profession. Many entries also relate to veterinary science. Obsolete words and expressions, duplications and repetitions have been eliminated while terms relating to botany, homœopathy, eclectic medicine, life insurance and electricity are also omitted unless they have medical applications.

Such wholesale alteration has meant a resetting of the entire work. The publishers have consequently used a new type face and arrangement which make the entries much easier to find and read. The pages are larger and there are many more of them. Pronunciations are given only where the editors consider English-speaking readers might have difficulties. With the vastly improved illustrations, the high-quality paper and the sturdy binding, Stedman's Medical Dictionary in its twentieth edition is so new that it resembles the first one only in bearing the name of Stedman. Although prepared in the United States. the producers had all English-speaking readers in mind during the production and the dictionary can be recommended to all who read English as remarkable value for money. $\quad$ K. M. HAwkINs 